\title{
Advantages and caveats of using Nd isotopic compositions of sedimentary rocks to trace continental sources and history: insights from global databases
}

\author{
MARION GARÇON
}

CNRS - University Clermont Auvergne

Presenting Author: marion.garcon@uca.fr

Neodymium isotopic compositions of sediments have been widely used to investigate the composition of continents and their geological history assuming that weathering, transport, and sedimentation did not fractionate the $\mathrm{Sm}-\mathrm{Nd}$ isotopic system. Potential biases by sedimentary processes have been reported by few studies $[1,2,3]$ but it is difficult to evaluate how reliable is the $\mathrm{Nd}$ proxy at the scale of the global sedimentary system. Advantages and caveats in the use of sediment $\mathrm{Nd}$ isotopes as a source proxy are here discussed based on two global compilations. The first compilation includes $\mathrm{Nd}$ isotopic composition of modern sediments delivered at the mouth of major world rivers $(\mathrm{N}-=60)$. The second compilation includes $\mathrm{Sm}-\mathrm{Nd}$ data of fine- and coarse-grained sedimentary rocks deposited over the past $3.7 \mathrm{Ga}$ all over the world $(\mathrm{N}=2650)$.

The isotopic record of fine- and coarse-grained sedimentary rocks are compared to evaluate (1) the effects of hydrodynamic sorting during sediment transport and (2) preferential erosion of mafic lithologies in fine-grained sediments. Global compilations demonstrate that, while local effects are observed for a few river systems and specific periods of time, no systematic bias as a function of sediment grain-size is identifiable at the scale of the global sedimentary system and over geological time.

Preferential erosion of juvenile crust with radiogenic $\mathrm{Nd}$ isotopic signature has also been suggested as a potential caveat in the use of $\mathrm{Nd}$ isotopes to trace continental sources. The rationale behind this being that juvenile crust was preferentially exposed in areas of high reliefs where erosion is maximal, hence is overrepresented in sediments. Hydrological data for major world rivers confirm that river sediment loads are positively correlated with relief, hence that erosion is maximal in areas of high topography. However, river sediment loads are not correlated with sediment $\mathrm{Nd}$ isotopic compositions and rivers with the highest sediment loads do not preferentially sample juvenile crust. These observations indicate that there is no obvious sampling bias towards juvenile crust in the $\mathrm{Nd}$ isotopic record of sedimentary rocks at the global scale.

[1] Allègre and Rousseau, EPSL, 1984; [2] Garçon and Chauvel, EPSL, 2014; [3] Bayon et al., GCA, 2015) 